\title{
Yaşılıarda Düşmeye Yol Açan Faktörler ve Koruyucu Rehabilitasyon Yaklaşımları
}

\section{Factors which Lead to Falls in Elderly and Preventive Rehabilitation Approaches}

\author{
Nejla UZUN ${ }^{\mathrm{a},}$ Yasemin ŞAHBAZ $^{\mathrm{b}}$, Ela TARAKCI ${ }^{\mathrm{c}}$
}

ÖZET Dünya Sağlık Örgütü gelişmekte olan ülkelerde yaşlı nüfusun artış göstereceğini bildirmektedir. Türkiye'de de Dünya'nın her yerinde olduğu gibi yaşlı nüfusta artış olması beklenmektedir. Yaşlanma ile beraber sık sık fonksiyonel durumda gerileme ve fiziksel inaktivite nedeniyle denge kayıpları ve sonrasında düşmeler görülmektedir. Bu derlemedeki amacımız, yaşlılarda denge sorunlarını incelemek, düşme ile ilgili risk faktörlerini belirlemek ve bunlara karşı geliştirilebilecek koruyucu rehabilitasyon yaklaşımlarını tartışmaktır. Denge bozukluklarına yol açan problemlerin oluşmasını önlemek, denge reaksiyonlarını geliştirmek, düşmelere yol açabilecek etkenlerin erken dönemde tedavi edilmelerini sağlamak ve kalıcı problemlerin etkilerini en aza indirmek koruyucu rehabilitasyonun amaçlarını oluşturmaktadır. Bu amaçları gerçekleştirmek için her yaşlının kendine özgü sağlık durumu dikkate alınarak primer, sekonder ve tersiyer koruma olmak üzere üç farklı koruyucu rehabilitasyon yaklaşımı belirlenmiş̧tir. Rehabilitasyonda primer koruma herhangi bir hastalık oluşmadan önce alınabilecek önlemleri ifade eder. Sekonder koruma erken tanı, uygun tedavi ve komplikasyonların sınırlandırılmasından oluşur. Tersiyer koruma, ortaya çıkmış hastalığa bağlı olarak oluşabilecek sakatlık ve geri dönüşü olmayan bozuklukların en aza indirgenmesi, hastanın bu durumuna alışması sağlanarak yaşam kalitesinin artırılması için alınması gereken önlemlerdir. Bu derlemede yaşlılarda düşmeye yol açan faktörler ve koruyucu rehabilitasyon yaklaşımları bu prensipler çerçevesinde ayrıntılı olarak ele alınmıştır.

Anahtar Kelimeler: Yaşli, Postural Denge, Düşmeler

\begin{abstract}
World Health Organization has announced that the population of the elderly would increase in the developing countries. As it happens everywhere in the world, an increase is also expected in Turkey among the population of the elderly. Alongside with aging, frequently a decline in functional state and loss of balance and fallings due to physical inactivity has been observed. Our purpose in this edition is to analyze the problems of balance among the elderly, determine the risk factors in regards to falling, and discuss the preventive rehabilitation approaches to be developed against them. Preventing the problems leading to equilibrium disorders and improving the balances, ensuring that the factors that may lead to falls are treated in the early stages, and the effects of permanent problems are the most important goals of preventive rehabilitation. To realize those purposes, three different protective rehabilitation approaches have been determined such as the primary, secondary and tertiary protection by taking every elderly's distinctive health situation into account. Primary protection in rehabilitation refers to the precautions that may be taken before formation of any sickness. Secondary protection is composed of early diagnosis, proper treatment and limitation of complications. Tertiary protection is the least costly disability and irreversible disorders that can occur due to emerging disease and encourages the patient to take precautions to adapt to this situation and increase the quality of life. Factors which lead to falls in elderly and preventive rehabilitation approaches in this review are covered detail in the framework of these principles.
\end{abstract}

Key words: Elderly, Postural Balance, Falls

\section{Giriş}

Yaşlanma, kronolojik, biyolojik, psikolojik ve sosyal niteliği olan, intrauterin dönemde ortaya çıkıp, ölümle sonlanan farklılaşma sürecidir (1). Fizyolojik olarak bakıldığında ise, fiziksel ve ruhsal sağlığın bozulması, organizmanın iç ve dış etmenler arasındaki dengeyi sağlama yeteneğinin azalması, kişinin psikolojik yönden gerilemesi olarak tanımlanabilir (2).
Fiziki uygunluk, yaşlı kişilerde sağlıklı yaşam ve bağımsızlık için çok önemlidir. Yaşlanma süreci ile birlikte genellikle fiziksel aktivite ve fonksiyonellikte gerileme gözlenmektedir. Buna ek olarak sedanter yaşam süren yaşlıların kuvvet, endurans ve esneklikte azalma ile fonksiyonelliklerinin etkilendiği görülebilmekte ve kişiler olağan aktiviteleri yapabilmek için daha çok çaba harcamaktadırlar.

Geliş Tarihi/Received: 13-10-2017 / Kabul Tarihi/Accepted: 24-01-2018

a. Uzm. Fzt., İstanbul Üniversitesi, Sağlık Bilimleri Enstitüsü, İstanbul

b. Uzm. Fzt., Üniversitesi, Beykent Üniversitesi Tıbbi Hizmetler ve Teknikler Bölümü, Fizyoterapi Programı

c. Doç.Dr., İstanbul Üniversitesi, Sağlık Bilimleri Fakültesi, İstanbul

Sorumlu yazar /Correspondence: Uzm. Fzt. Nejla Uzun, İstanbul Üniversitesi, Sağlık Bilimleri Enstitüsü,

İstanbul e-posta: fizyoterapist_nejla@hotmail.com 
İşlevsel bozuk lukların neden olduğu fiziki yetersizlik ve sonrasında oluşan düşmelerin önlenmesi için, fiziki uygunluktaki değişikliklerin erken dönemde tanımlanması ve uygun egzersiz programlarının geliştirilmesi önemlidir (3).

Yaşın artmasıyla görülme sıklığı da artan düşmeler yaşlı kişilerde önemli oranda mortalite ve morbiditeye sebep olan bir sağllk problemidir. Kişisel ve çevresel faktörlerin etkileşimiyle oluşan düşmeler kişilerde birçok fiziksel ve ruhsal sonuçları ortaya çıkarmaktadır. Birçok yaşlı, düşme olayı yaşamadan bu durumun önemini bilmemekte ve oluşmaması için önlem almamaktadır. Ancak düşmeye bağlı bir olumsuzluk yaşadıktan sonra düşmeden korunma ile ilgili önlemler almaktadır (4). Bu derlemedeki amacımı, yaşlılarda denge sorunlarını incelemek, düşmeye yol açan faktörleri belirlemek ve bunlara karşı geliştirilebilecek koruyucu rehabilitasyon yaklaşımlarını tartışmaktır.

\section{Yaşlılığa Genel Bakıs}

Dünya Sağlık Örgütü (DSÖ) yaşl11ığı üç dönemde sınıflandırmıştır. Birinci dönemi 45-59 yaş aras1 orta yaşlılar, ikinci dönemi 60-74 arasındaki yaşlılar ve üçüncü dönemi 75 yaş ve üzeri ileri derecede yaşlılar oluşturmaktadır. DSÖ, gelişmekte olan ülkelerde yaşlı nüfusunun daha fazla artış göstereceğini, 65 yaş ve üstü insan sayısının 2010 yilında 524 milyon olduğunu ve 2050 yılında ise 1,5 milyara ulaşacağını bildirmektedir (5). Türkiye'de de yaşlı nüfusta artış beklenmektedir. Türkiye İstatistik Kurumunun (TUIKK) 2013 y1l verilerine göre Türkiye yaşlı nüfus oranı $\% 7,7$ olarak gösterilmektedir (6). TUIK 2015 verilerine göre ise yaşlı nüfusunun (65 ve üzeri yaş) 6.495.239 kişi olduğu belirtilmektedir (7). Ayrıca2030, 2040 ve 2050 yıllarında Türkiye'de 65 yaş üzeri nüfusun toplam nüfusun sirasıly $\% 10,8$ 'ini, $\% 13,6$ 'sın1 ve \%17,3'ünü oluşturmas1 beklenmektedir (8). Yaşlanmayla birlikte kardiyovasküler sistemde, pumoner sistemde, gastrointestinal sistemde, sinir sisteminde ve kas iskelet sisteminde fizyolojik değişimler meydana gelir (9). Bu değişimlerin sonucunda yaşl1larda denge olumsuz yönde etkilenir.

\section{Kardiyovasküler sistem değişiklikleri:}

Yaşla birlikte myokardın atrofiye uğramasına bağl1 olarak kalbin her bir kasilmasında pompalanan kan miktarı, kalp hızı, kardiyak dolum hacmi ve tüm organlara giden kan akımı azalır. Bunun yanı sıra arterlerin esnekliğinin azalması; periferal dirençte, sistolik ve diyastolik kan basıncında artışa neden olur. Yaşla birlikte büyük elastik arterlerin, kompliyanstaki azalma sonucu damarlar dilate hale gelir (9).

\section{Pulmoner sistem değişiklikleri:}

Rezidüel hacimde artış, kanın oksijenlenmesinde azalma, ventilasyon perfüzyon eşitliğinde azalma, akciğer elastisitesinde azalma, gögüs kafesi kompliyansında azalma görülür. Buna ek olarak vital kapasite ve maksimum inspiratuar kapasite yaşlanma ile \%35-65 oranında azalır. Değerlerdeki bu azalma yaşla birlikte yeterli gaz değişimi yapılamamasına ve aktiviteler sırasında çabuk yorulmaya neden olur (10).

\section{Gastrointestinal sistem değişiklikleri:}

Yaşlanmanın gastrointestinal sistemdeki genel etkisi hareket, salg1 ve emilim kapasitesinde azalmadır. Özofageal motilite azalır, yutkunma zorlukları başlar. Midede ise gastrik motilitede ve sekresyonlarda azalma ve gastrik boşalma zamanında artma söz konusudur. Ayrıca hepatik kütle ve lokal kan akımında azalmalar meydana gelir (1).

\section{Kas iskelet sistemi değişiklikleri:}

Yaşla birlikte kemiklerin yoğunluğunun azalmasına bağlı olarak kemikler daha zayıf ve kırılgan hale gelirken, vücut postürü de bozulmakta olup boy kısalması, diş kayıpları, kemiklerde kırılmalar, bacaklarda eğrilikler ve kamburlaşma gelişebilir. Kas dokusu kayıplarına bağlı olarak gelişen atrofiler, kas gücünde ve koordinasyonunda azalmalara neden olup günlük yaşam aktivitelerini yapmayı zorlaştırır ve dururken, yürürken denge sorunlarına yol açar (10).

\section{Sinir sistemi değişiklikleri:}

Yaşla birlikte sinir iletim hızında ve beyindeki nöron sayısında hızla azalma görülür. Buna bağlı olarak reaksiyon ve hareket zamanında düşüş, reflekslerde azalma meydana gelir. Sinir sistemi değişiklikleri sonucu serebrovasküler olay, alzheimer, demans, parkinson hastalığ deliryum, depresyon gibi bilişsel, motorik ve duyusal problemler görülür (9).

\section{Denge}

Destek tabanı üzerinde vücudun kontrolünün sağlanarak düşmenin önlemesi yeteneğidir. Dik duruş postürünün sağlanması ve aktiviteler sırasında dengenin devam ettirilebilmesi için, 
oldukça karmaşık nöromusküler mekanizmalar gereklidir. $\mathrm{Bu}$ mekanizmalar çeşitli duyusal kaynaklardan (propriyoseptif, görsel, vestibüler) vücudun yönelimi ve hareketleri ile ilgili bilgi elde eden ve bu bilgiyi ağırlık merkezini destek merkezi üzerinde tutma konusunda uygun motor cevap üretmek için kullanan sinir kas etkileşiminden oluşmaktadır. Duyusal veriler, merkezi sinir sisteminde birleștirilerek, retiküler formasyon, ekstrapiramidal sistem, serebellum ve korteksden çıkan uyarılar ile modüle edilir. ${ }^{11}$ Yaşlanmaya bağlı olarak nöral sistemin birçok duyusal elemanı entegre etmedeki yetersizliği yaşlılardaki düşme risk faktörlerden biri olabilir (12).

\section{Yaşa Bağlı Değişikliklerin Yol Açtığı Denge Problemleri}

Yaşlanmayla beraber postüral kontrolde; ayak bileğinden gelen propriyoseptif veride azalma, görsel netlikte azalma, postüral salınımda artma, vestibüler sistem reseptörlerinde azalma, derinlik algısında kayıp, kuvvette azalma, MSS'nin ileti hızında azalma, kemik mineral yoğunluğunda azalma, artmış reaksiyon zamanı, yana gövde salınımında artma ve eklem hareket açıklığında azalma gibi değişiklikler görülür.

Yaşlıların salınım miktarı ve normal salınım aralığı gençlere göre daha büyüktür. Yaşlılarda kalça rotasyonun ve diz fleksiyonunun azalmasına bağlı olarak salınım fazında ekstremitenin daha az kaldırılması sonucunda takılma ile düşme eğilimi artar. Yaşlılar yürürken takıldıklarında veya kaydıklarında gençlere göre daha zor toparlanırlar ve genellikle düşmeler meydana gelir. Bazı yaşlılarda MSS tarafindan dik duruşu ve yürüyüşü kontrol eden nöromusküler kuvvetlerin başarıyla koordine edilememesi direkt düşme sebebidir (13). Altmış beş yaş üzeri kişilerin \%30' u, dengelerini korumalarını zorlaştıracak ilerleyici denge ve postür bozukluğuna sahip oldukları için düşmektedirler (12).

Sağlıklı kişilerde denge kaybı olduğunda sırasıyla vücut salınımı, adım atma ve ani ekstremite hareketi oluşurken, bunlardaki başarısizlık koruyucu ekstansiyon refleksi ortaya çıkarır. Ancak bu mekanizmaların yaşlı kişilerde zayıfladığı gözlenir (14).

Postüral kontrol vizüel sistem, vestibüler sistem, propriyosepsiyon ve spinal gerilme refleksleriyle gerekli bilgiler sağlanması ve bu bilgilerin merkezi sinir sisteminde entegrasyonu yoluyla ortaya çıkar. Yaşlanmayla birlikte duyusal ve motor sinir sistemi etkilenerek postüral salınımın artmasına neden olur. Buna bağlı olarak da yaşlılarda düşme riski artmaktadır (13).

\section{Düşme}

Kompleks bir yapıya sahip olan düşmeler, birçok faktörden etkilenmekte olup yaşlilarda en çok görülen morbidite ve mortalite sebeplerindendir (15). Altmış beş yaş üzeri popülasyonun yaklaşık üçte biri her yıl düşmekte ve düşmelerin yarısını ise tekrarlayan düşmeler oluşturmaktadır (14). Yetmiş yaş üzerindeki yaşlılarda bir yıl içindeki düşme oran1 \%32-42 iken, 80 yaş üzerindekilerde ise bu oran \%50'dir (16). Düşmenin risk faktörleri intrinsik ve ekstrinsik olacak şekilde ikiye ayrılabilir. İntrinsik faktörler yaşlı kişinin kendisine bağlı olan veya kendisinden kaynaklanan faktörlerdir. Ekstrinsik faktörler yaşlı kişinin kendisine bağlı olmayan çevre şartlarının oluşturduğu faktörlerdir (17).

İntrinsik faktörler: Yaş, cinsiyet, postüral kontrolde kayıp, yardımcı cihaz kullanımı, anormal yürüyüş paterni, reaksiyon zamanının azalması, kas güçsüzlüğü, artrit, serebrovasküler hastalık, periferik nöropati, parkinson hastalığı, demans, görme problemleri, göz kararması (senkop, hipoglisemi, postural hipotansiyon, kardiak aritmi, epilepsi, alkol, ilaçlar, vertebrobaziller yetmezlik), menier hastalığ dört veya daha fazla sayıda ilaç kullanımı intrinsik faktörler içinde yer almaktadır (17-20).

Ekstrinsik faktörler: Yeterli aydınlatmanın olmaması, korkuluksuz merdivenlerin olmas1, banyo küvetinin etrafinda ve tuvalette tutunma barlarının bulunmaması, banyo küvetinin zemininin ve yer halılarının kaygan olması, tuvalette oturma yerinin uygun yükseklikte olmaması, yaya kaldırımlarının düzgün zeminli olmaması, kar, buz, protez, baston ya da yürüteç kullanmak düşmeye sebep olan ekstrinsik faktörler içinde yer almaktadır.

Yaşlı kişilerde genellikle yürüme, pozisyon değiştirme, sandalye veya merdivene çıkma aktiviteleri ile spor yapma esnasında düşmelerin geliştiği bildirilmektedir (21). Ülkemizde yaşlı kişilerin \%10'unun sağlık bakım kurumlarında, \%30'unun toplumsal alanlarda ve $\% 60$ 'ının ev ortamında düştüğü belirtilmektedir. Merdivenden inmenin çıkmaktan daha zor ve tehlikeli olduğu ve düşmelerin \%10'unun merdivende meydana geldiği belirtilmektedir (17). Yaşliların en çok banyo ve tuvalette düştügüne yer verilmektedir (22). 


\section{Düşme Korkusu}

Düşme korkusu, düşme ile ilgili artmış endişe veya kişinin günlük yaşam aktiviteleri sırasında düşmenin önlenmesinde düşük öz etkinlik olarak tanımlanmaktadır (23). Düşme sonunda yaralanmış yaşl1ların üçte birinde düşme korkusu gelişmektedir. Yaş, cinsiyet, denge ve yürüme bozuklukları, zayıf fiziksel ve kognitif fonksiyonların yaralanmayla sonuçlanan düşmelere bağlı oluşan düşme korkusu ile ilişkili olduğu bulunmuştur (24). Düşme korkusu ile beraber yaşlı kişilerin fiziksel fonksiyonlarında kısıtlanma, mobilitelerinde ve yaşam kalitesinde azalma gözlenebilmektedir (25). Düşme korkusuyla ilişkili faktörlerin bilinmesi düşme korkusunun azaltılması ve yaşam kalitesinin artırılması için önemlidir (25). Park JH ve ark.'nın 60 yaş ve üzeri 883 katılımcı ile yaptıkları çalışmada düşme deneyiminin, düşme korkusu ve fiziksel performans ile önemli bir ilişki içinde olduğu bulunmuştur (26). Türkiye'de 65 yaşındaki bireylerin düşme hikayeleri incelendiğinde meydana gelen düşmelerin \%60'ının ev ortamında, \%30'unun sosyal alanlarda, \%10'unun sağlik bakım kurumlarında meydana geldiği görülmüştür (25). Yaşlılarda görülen düşme oranlarına basitçe yükssek demek yeterli değildir. Çünkü düşme oranının artmasıyla birlikte, kanser, osteoporoz gibi hastalıklarda artma, koruyucu reflekslerde yavaşlama gibi fizyolojik değişikliklerin meydana gelmesi düşmeyi daha da tehlikeli bir hale getirmektedir (27).

\section{Koruyucu Rehabilitasyon Yaklaşımları}

Denge ve düşme problemi olan yaşliların koruyucu rehabilitasyonunda amaç denge bozukluklarına yol açan problemlerin oluşmasını önlemek ve dengelerini daha iyi hale getirmek, düşmelere yol açabilecek intrinsik ve ekstrinsik etkenleri erken dönemde tedavi edilmelerini sağlamak, kronik hale dönüşmüş bir problem varsa gerekli önlemler alarak kalıcı problemlerin etkilerinin en aza indirmektir. $\mathrm{Bu}$ amaçları gerçekleştirmek için her yaşlının kendine özgü sağlık durumu dikkate alınarak üç farklı koruyucu rehabilitasyon yaklaşımı uygulanabilir.

\section{Primer Koruma}

Rehabilitasyonda primer koruma herhangi bir hastalık oluşmadan önce alınabilecek önlemleri ifade eder. Yaşlanmayla birlikte görülen fizyolojik değişikliklerin de etkisiyle zamanla ortaya çıkacak problemler ve bunlara bağlı oluşabilecek komplikasyonlar da primer koruma yöntemleriyle önlenebilir ya da azaltılabilir. $\mathrm{Bu}$ kapsamda primer koruma çocukluktan itibaren fiziksel aktivite, egzersiz, yeterli ve dengeli beslenme alışkanlıklarının kazandırılması; sigara, alkol gibi bağımlılık yapan zararlı alışkanlıklardan uzak durulmasını içermektedir.

İskelet büyümesi sırasında doruk kemik kütlesine ulaşmak çok önemlidir. Vitamin D kalsiyum emiliminde, kemik sağllğ 1 üzerinde, kas performansında ve düşme riskinin azalmasinda majör rol oynar. Yeterli Ca, D vitamini ve protein içeren dengeli bir diyetin yanı sıra çocukluk ve adolesan dönemden itibaren kemiklere stres oluşturan düzenli fiziksel aktivite ve egzersiz de gereklidir (28). Düzenli fiziksel aktivite birçok sistem ve organ fonksiyonu üzerinde yararlı olmaktadır. Kemikler, kaslar, ligamentler ve tendonların kuvveti artar. Kardiyovasküler risk faktörlerini azaltır. Osteoporozu azaltır. Hareket sistemini güçlendirerek hareket özgürlügünü, günlük işlerini yapabilme kapasitesini artırır. Düzenli fiziksel aktivite yapmamış yaşlı kişilerde dahi düzenli egzersiz programı ile yaşam kalitesi ve yaşam süresinin arttırdığı gösterilmiştir (29). Bu yüzden çok erken yaşta fiziksel aktivitenin özendirilmesi ve bu konuda kişilerin bilgilendirilmesi gerekmektedir.

\section{Sekonder Koruma}

Rehabilitasyonda sekonder koruma erken tan1, uygun tedavi ve komplikasyonların sınırlandırıl--masından oluşur. Sekonder önlemler, dengeyi bozacak ve düşmelere neden olacak faktörlerin ortadan kaldırılmasını, dengenin geliştirilmesi böylece düşmelerin ve düşmeye bağlı oluşabilecek problemlerin önlenmesini içerir.

Düzenli egzersiz programı östrojen artışı, insülin ve androjen gibi intrinsik endokrin faktörleri serbestleştirerek kemik ve kasın güçlenmesini sağlayarak kemik kitlesindeki kaybı yavaşlatır, kemik kütlesini artırır ve kırığı önler. Ayrıca dengeyi sağlayarak düşmeleri önler, kardiovasküler hastalık riskini azaltır, bazal metabolik hizı artırır/korur, endurans1 artırır, ruhsal sağlığı korur (30). Karikanta ve ark. yaşlı yetişkinlerde düşme ve kırıkların önlenmesi için en etkili fizik tedavi yaklaşımının denge ve kuvvetlendirme eğitimi kombinasyonunun olduğunu göstermiştir (31). Çok faktörlü koruyucu programların yüksek riskli popülasyonlarda etkili olabilmesi için, bireysel uyarlanmış önlemleri ve egzersiz bileşenini içermesi gerekir. Dengeyi geliştirerek düşmelerin önlenmesine yönelik uygun egzersiz. 
Tablo 1. Yaşlılarda kullanılabilecek egzersiz çeşitleri ve reçetesi (33-35).

\begin{tabular}{|c|c|c|c|c|}
\hline EGZERSİZ TİPİ & FREKANS & YOĞUNLUK & SÜRE & İLERLEME \\
\hline Aerobik & Haftada 3 gün & МKH \%50 & $20-30 \mathrm{dk}$ & $\begin{array}{l}\text { İki haftada bir } \% 5 \\
\text { artırarak kademeli } \\
\text { ilerleme ve } \% 70 \\
\text { düzeyini aşmamalıdır }\end{array}$ \\
\hline Kuvvetlendirme & $\begin{array}{l}\text { Haftada } 3 \text { gün } \\
\text { Her set } 8-12 \text { tekrar }\end{array}$ & 1 MT'1n \%40-60 & $45-60 \mathrm{dk}$ & $\begin{array}{l}1 \quad \text { MT'1n \%60-80'e } \\
\text { çıartılabilir }\end{array}$ \\
\hline Germe & Haftada 2 ile $3 \mathrm{kez}$ & Statik $15-60 \mathrm{sn}$ & $\begin{array}{l}\text { Minumum } 10 \mathrm{dk} \text { her kas } \\
\text { grubuna } 4 \text { ve üzeri tekrar }\end{array}$ & $\begin{array}{lr}\text { Tolerasyona } & \text { göre } \\
\text { tekrar sayıs1 ve süre } \\
\text { kademeli } \\
\text { artırılmalıdır }\end{array}$ \\
\hline Tai Chi Chuan & Haftada $7 \mathrm{kez}$ & MKH \%55 & $\begin{array}{l}10 \mathrm{dk} \text { 1sınma } \\
40 \mathrm{dk} \text { TCC egzersizleri } \\
10 \mathrm{dk} \text { soğuma } \\
\text { Toplam } 1 \text { saat }\end{array}$ & $\begin{array}{l}\text { Tolerasyona göre süre } \\
\text { kademeli olarak } \\
\text { artırılmalıdır }\end{array}$ \\
\hline Klinik Pilates & Haftada 3 kez & MKH \%40-60 & $20-30 \mathrm{dk}$ & $\begin{array}{lr}\text { Tolerasyona } & \text { göre } \\
\text { tekrar sayısı ve süre } \\
\text { kademeli } & \text { olarak } \\
\text { artırılmalıdır } & \end{array}$ \\
\hline Otago & Haftada $3 \mathrm{kez}$ & $\% 50-60$ & 1 saat & $\begin{array}{l}\text { Önce süre ve frekans } \\
\text { arttırılmalı, sonrasında } \\
\text { hastanın durumuna } \\
\text { göre istenen düzeye } \\
\text { ulaşıldığında egzersiz } \\
\text { şiddeti arttırılmalıdır }\end{array}$ \\
\hline
\end{tabular}

MKH: maksimum kalp atım hızı; Dk: dakika; Sn: saniye; 1 MT: bir maksimum tekrar; TCC: Tai Chi Chuan

program1, aerobik egzersizleri, postür egzersizlerini, kuvvetlendirme ve fleksibilite egzersizlerini, denge ve yürüme eğitimlerini içermelidir. Dengenin geliştirilmesinde dinamik ve statik denge egzersizleri önemlidir (32). Uygun egzersiz programı iyi bir değerlendirme sonrasında kişiye özel olarak hazırlanmalıdır (Tablo 1).Yaşlilar için literatürde önerilen egzersizlerden 12 hafta boyunca düşük yoğunlukta uygulanan Thai Yoga'nın yaşlı erişkinlerde fiziksel işlevlerinde, sağlık ve iyilik hallerinde önemli iyileşmeler sağladığ 1 gösterilmiştir (36). Granacher ve ark.'nın yaptıkları sistematik derlemede yaşlı erişkinlerde core stabilizasyon kuvvet eğitimi ve Pilates egzersiz eğitiminin güç, denge, fonksiyonel performans ölçümleri ve düşme yönünde olumlu bir etkiye sahip olduğu gösterilmiştir. Temel güç antrenmanının ve pilates egzersiz eğitiminin, yaşlılar için geleneksel denge ve direnç eğitim programlarına ek olarak kullanılabileceği belirtilmiştir (37). Düşmelerin önlenmesi için öncelikle düşmeye neden olabilecek risk faktörleri belirlenmelidir. Yaşlılar bu riskler konusunda bilgilendirilmeli, yaşlı ve ailesi eğiti- lerek çevredeki risk faktörleri önlenmeye çalışılmalıdır. Düşmeye neden olan diş etkenleri değerlendirilip uygun düzenlemelerin yapılması ile düşmede risk faktörü olan çevresel etmenler en aza indirgenerek yaşlının düşme riskini azaltılır ve yaşam kalitesini arttırılır (Tablo 2) (38).

\section{Tersiyer koruma}

Rehabilitasyonda tersiyer koruma hastalık oluştuktan sonra meydana gelebilecek problemleri en aza indirgemek ve hastayı bu durumuna alıştırarak yaşam kalitesinin arttırmak için alınması gereken önlemleri tanımlar. Denge problemleri sonrasında oluşan düşmelere bağl1 kırık, yumuşak doku hasarı, beyin travması vb. durumlara yönelik ve sonrasında oluşabilecek düşme korkusuna karşı yapılan tedavileri ve alınacak önlemleri içerir. Ancak birincil ve ikincil koruma yöntemlerinin mümkün oldugunca erken dönemde uygulanması ve bu aşamaya gelmeden önlenmesi büyük önem taşımaktadır. 
Tablo 2. Yaşlılarda düşme riskini azaltıcı ekstrinsik ve intrinsik faktörler (38-39).

Merdivenler Basamakların aralıkları ve yükseklikleri eşit olmalı ve çıkıntılar ve uygunsuz basamak uygulamaları takılıp düşmeye neden olabileceği için olmamalıdır. Basamaklarda kaymayı engellemek için kaydırmaz malzemeler kullanılmalı, halı ve kilimler tercih edilmemelidir. Elektrik düğmeleri merdivenlerin başında ve sonunda uzanılabilecek yükseklikte olmalıdır. Uzun merdivenlerde tutamak ve dinlenebilmek için alanlar olmalıdır.

\begin{tabular}{|c|c|c|}
\hline \multirow{5}{*}{ 离 } & Antre & $\begin{array}{l}\text { Mobilyalar, duvar boyunca ve köşelere yerleştirilmelidir. Askılar kolayca } \\
\text { ulaşılarak eşyaların asılmasına olanak sağlamalıdır. }\end{array}$ \\
\hline & Oturma Odas1 & $\begin{array}{l}\text { Sandalye ve kanepeler rahatça oturup kalkılabilecek yükseklik ve derinlikte } \\
\text { olmalıdır. Kolay yanmayan, kaygan olmayan kumaşlardan yapılmış canlı } \\
\text { renklerdeki mobilya döşemeleri tercih edilmelidir. Kenarları kalkık, kıvrık ve } \\
\text { göz yorucu şekilde karışı desenli halılar seçilmemeli, elektrik kabloları ve } \\
\text { sehpalar yürümeyi zorlaştıracak şekilde yerleştirilmemelidir. }\end{array}$ \\
\hline & Yatak Odası & $\begin{array}{l}\text { Yatak odası banyo ve tuvalete yakın planda olmalı, etrafta koltuk değneği, } \\
\text { baston ya da tekerlekli sandalye ile dolaşımı engelleyecek eşyalar olmamalıdır. } \\
\text { Yatak odasının aydınlanması iyi olmalı, yatak başı lamba kullanılmalıdır. }\end{array}$ \\
\hline & Mutfak & $\begin{array}{l}\text { Mutfak dolabı rafları kişinin kolayca uzanabileceği yükseklikte olmalıdır. Masa } \\
\text { ayakları içeriye çıkıntılı olmalıdır. Çarpmaları önlemek için masa kenarları } \\
\text { keskin olmamalıdır. Arıza anında tehlike oluşturmaması için otomatik gaz } \\
\text { kesim sistemi olmalıdır. }\end{array}$ \\
\hline & Banyo/Tuvalet & $\begin{array}{l}\text { Banyo zemini kaymayı önleyici ve parlamayan malzemeden yapılmalıdır. } \\
\text { Döşemeler ıslak bırakılmamalıdır. Duvarlara hareketleri kolaylaştırmak için } \\
\text { yatay eksende iyi sabitlenmiş tutunma barları konulmalıdır. Kaymayan terlikler } \\
\text { kullanılmalıdır. Havalandırma sistemi rahatça ulaşılacak yükseklikte olmalıdır. }\end{array}$ \\
\hline \multirow{4}{*}{ 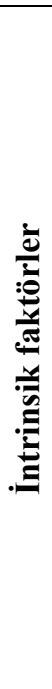 } & $\begin{array}{l}\text { Ayak sorunları ve } \\
\text { ayakkabı seçimi }\end{array}$ & $\begin{array}{l}\text { Ayak sorunları nedeniyle gelişen immobilite, yaşlıların sosyal yaşantılarını ve } \\
\text { yaşam kalitelerini büyük oranda sınırlandırmaktadır. Bunu önlemek için } \\
\text { kullanılan ayakkabıların uygunluğuna dikkat edilmelidir. Duyu kaybı, } \\
\text { deformite, cilt hassaslaşması, nasır ve tırnak sorunlarında giyilecek ayakkabının } \\
\text { bu durumlara uygun seçilmesi için gerekirse bir yardım alınması gerekmektedir. } \\
\text { Yüksek topuklu ayakkabılardan kaçınılmalı, rahat, geniş, ince ve sert tabanlı, } \\
\text { ayak bileğini saracak kadar yüksek boyunlu ayakkabılar seçilmelidir. }\end{array}$ \\
\hline & Kullanılan İlaçlar & $\begin{array}{l}\text { Benzodiazepinler ve diğer sedatif ilaçlar, antihipertansif, antidepresan gibi } \\
\text { düşmeye neden olabilecek ilaçların kullanımında ve dörtten fazla ilaç } \\
\text { kullanımında mümkün olan azaltmalar yapılmalıdır. }\end{array}$ \\
\hline & Yardımcı cihazlar & $\begin{array}{l}\text { Yardımcı cihaz kullanılarak eklemlere binen yük azaltılır, destek yüzeyi } \\
\text { genişlediği için stabilite artar. }\end{array}$ \\
\hline & Kıyafet seçimi & $\begin{array}{l}\text { Takılıp düşmelere sebep olacak uzun, bol, kıyafetlerin, seçilmemesine dikkat } \\
\text { edilmelidir. }\end{array}$ \\
\hline
\end{tabular}

\section{Sonuç}

Yaşlılarda düşme, yaygın olarak karşıllaşılan bir problemdir ve genellikle intrinsik, ekstrinsik ve duruma bağlı faktörlerin kompleks etkileşimi sonucu meydana gelir. Düşme sonrasında kırık, bakım ihtiyacında artma, düşme korkusu, aktivite ve bağımsızlıkta azalma ve hatta ölüm görülebilmektedir. Yaşlılarda düşmelere neden olabilecek fizyolojik değişimlerin etkilerini en aza indirebilmek için primer koruma, komplikasyonların sınırlandırılması için sekonder koruma ve kalıcı bozuklukları en aza indirmek ve yaşam kalitesini artırmak için tersiyer koruma yöntemlerinin mümkün olan en erken dönemde uygulanmas1 bu yüzden büyük önem taşımaktadır. Bu makale, daha önce herhangi bir yayın organında yayımlanmamıştır. 


\section{Kaynaklar}

1. Beğer $T$, Yavuzer H. Yaşl1lık ve yaşl11ık epidemiyolojisi[Aging and aging epidemiology]. Klinik Gelişim [Clinical Development] 2012; 25(3):1-3.

2. Erbaş F, Akın A. Yaşlılık, sağlık ve kadın [Old age, health and woman]. Sağlik ve Toplum [Health and Society] 2008;18(34):1-10.

3. Chang $M$, Huang $Y$, Jung $H$. The effectiveness of the exercise education programme on fall prevention of the community dwelling elderly. Hong Kong Journal of Occupational Therapy 2011;21(2):56-63.

4. Terzi R, Terzi H. Geriatrik hastalarda tekrarlayan düşmeler ile ilişkili faktörler[Factors Associated with Recurrent Falls in Geriatric Patients]. FTR Bil Der [J PMR Sci] 2013;16(1):96-101.

5. Gökulu G, Uluocak S,, Aslan C, Bilir O. Çanakkale merkezindeki 65 yaş ve üzeri yaşlıların yaşam kalitesini etkileyen faktörler[The factors affecting the quality of life among 65 years or older individuals living in the city center of çanakkale]. Uluslararası Sosyal Araştırmalar Dergisi [The Journal of International Social Research] 2014;7(34):666-677.

6. Günsoy G, Tekeli S. Nüfusun yaşlanması ve ekonomik büyüme ilişkisi: Türkiye üzerine bir analiz [Population aging and economic growth relation: An analysis on Turkey]. Amme İdaresi Dergisi [Journal of Amme İdaresi] 2015;48(1):35-87.

7. Pınar ŞE, Demirel G. Huzurevinde yaşayan orta yaş ve yaşlı bireylerde günlük yaşam aktiviteleri, öz-bakım gücü ve yaşam doyumunun incelenmesi [Daily Life Activities, Self-Care Ability and Life Satisfaction in Middle-aged and Elderly People Living in Nursing Homes]. Yaşlı Sorunları Araştırma Dergisi[Elderly Issues Research Journal] 2016;9(1):39-52.

8. Akın A. [Social Gender and Ageism]. Aslan D, Ertem M, editörler.Yaşlı Sağlığı Sorunlar ve Çözümler. 1. Bask1. Ankara: 2012.p.1725.

9. Yıldırım B, Özkahraman Ş, Ersoy S. Yaşlilıkta görülen fizyolojik değişiklikler ve hemşirelik bakımı [Physiological Changes in Elderly and Nursing Care]. Düzce Üniversitesi Sağlık Bilimleri Enstitüsü Dergisi [Journal of Duzce University
Institute of Health Sciences] 2012;2(2):1923.

10. Cronin H, Kenny RA. Biology and physiology of aging. In: Walsh TD, Caraceni AT, Fainsinger R, Foley K ve ark. Palliative medicine. Geriatrics, Chapter 203. First Edition, Philadelphia, Saunders. 2009: 11239.

11. Balaban Ö, Nacır B, Erdem HR, Karagöz A. Denge fonksiyonunun değerlendirilmesi [The evaluation of balance function]. Fiziksel Tip ve Rehabilitasyon Bilimleri Dergisi [Journal of Physical Medicine and Rehabilitation Sciences] 2009;12(3):133139.

12. Ceceli E, Kocaoğlu S, Güven D, Okumuş M, Gökoğlu F, ve Yorgancioğlu R. Geriatrik hastalarda denge, yaş ve fonksiyonel durum ilişkisi [Relation of Balance, Age and Functional Status in Geriatric Patients]. Türk Geriatri Dergisi [Turkish Journal of Geriatrics] 2007;10(4):169-172.

13. Onat ŞŞ, Özişler Z, Köklü K. Osteoporotik yaşlilarda denge bozukluğu [Balance disorders in the osteoporotic elderly]. Türk Osteoporoz Dergisi [Turkish Journal of Osteoporosis] 2013;19(3):87-9.

14. Pasquetti P, Apicella L, Mangone G. Pathogenesis and treatment of falls in elderly. Clin Cases Miner Bone Metab. 2014;11(3):222-5.

15. Al-Aama T. Falls in the elderly:spectrum and prevention. Can Fam Physician 2011;57(7):771-6.

16. Monica R.Perracini, Luiza F.Teixeira, Juliane L. A. Ramos, Raquel S. Pires, Myrian S. Najas. Fall-related factors among less and more active older outpatients. Rev Bras Fisioter 2011:1-7.

17. Atay E, Akdeniz M. Yaşlilarda düşme, düşme korkusu ve bedensel etkinlik [Falls in Elderly, Fear of Falling and Physical Activity]. GeroFam [Gerofam Medicine Journal] 2011; 2(1): 11-28.

18. Bruce $\mathrm{J}$ et al. The design and development of a complex multifactorial falls assessment intervention for falls prevention: The Prevention of Falls Injury Trial (PreFIT). BMC Geriatr 2017;17(1):116.

19. Deandrea S, Lucenteforte E, Bravi F, Foschi $\mathrm{R}$, La Vecchia C, Negri E. Risk factors for falls in community-dwelling older people: a 
systematic review and meta-analysis. Epidemiology 2010;21(5):658-68.

20. Lord SR, Smith ST, Menant JC. Vision and falls in older people: risk factors and intervention strategies. Clin Geriatr Med. 2010;26(4):569-81.

21. Çınarlı T, Koç Z. 65 yaş ve üzeri yaşlılarda düşme risk ve korkusunun günlük yaşam aktiviteleri ve yaşam kalitesi üzerine etkisi [Effect Of Risk And Fear Of Falling On Quality Of Life And Daily Living Actıvities In Elderly Over 65]. Gümüşhane Üniversitesi Sağlı Bilimleri Dergisi[Gümüşhane University Journal of Health Sciences] 2015;4(4):660-679.

22. Smith AA, Silva AO, Rodrigues RA, Moreira MA, Nogueira JA, Tura LF. Assessment of risk of falls in elderly living at home. Rev Lat Am Enfermagem 2017;25(1):27-54.

23. Oh-Park M, Xue X, Holtzer R, Verghese J. Transient versus persistent fear of falling incommunity-dwelling older adults: incidence and risk factors. JAm Geriatr Soc. 2011;59(7):1225-31.

24. Scheffer AC, Schuurmans MJ, Van Dijk N, Van der Hooft T. Fear of falling: measurement strategy, prevalence, risk factors and consequences among older persons. Age Aging 2008; 37(1):19-24.

25. Greenberg SA. Analysis of Measurementtools of fear of falling for highrisk, community dwelling older adults. Clin Nurs Res 2012;21:113-30.

26. Park JH, Cho H, Shin JH, Kim T, Park SB, Choi BY, et al. Relationship among fear of falling, physical performance, and physical characteristics of the rural elderly.Am J Phys Med Rehabil2014;93(5):379-86.

27. Austin N, Devine A, Dick I, Prince R, Bruce D. Fear of falling in older women: a longitudinal study of incidence, persistence, and predictors. J Am Geriatr Soc 2007;55:1598-1603.

28. Dohrn IM, Hagströmer M, Hellenius ML, Stahle A. Gait Speed, Quality of Life, and Sedentary Time are Associated with Steps per Day in Community-Dwelling Older Adults with Osteoporosis. J Aging Phys Act. 2016;24(1):22-31.

29. Soyuer F, Soyuer A. Yaşlilık ve fiziksel aktivite [Older adults and physical activity].
İnönü Üniversitesi Tip Fakültesi Dergisi [J Turgut Ozal Med Cent] 2008;15(3):219-224.

30. Eskiyurt N. Osteoporoz rehabilitasyonunda fiziksel aktivite ve beslenme [Physical Activity and Nutrition in Osteoporosis Rehabilitation]. Türkiye Klinikleri Jinekoloji Obstetrik Özel Dergisi [Türkiye Klinikleri J Gynecol Obst-Special Topics] 2009;2(3):95100.

31. Karinkanta S, Piirtola M, Sievanen H, U usiRasi K, Kannus P. Physical therapy approaches to reduce fall and fracture risk among older adults. Nat Rev Endocrinol 2010; 6(7):396-407.

32. Chang YC, Wang JD, Chen HC, Hu SC. Aerobic-synergized exercises may improve fall-related physical fitness in older adults. J Sports Med Phys Fitness 2017; 57(5):660669.

33. Sherrington C, Tiedemann A, Fairhall N, Close JC, Lord SR. Exercise to prevent falls in older adults: an updated meta-analysis and best practice recommendations. N S W Public Health Bull. 2011;22(3-4):78-83.

34. Bouaziz W, Vogel T, Schmitt E, Kaltenbach G, Geny B, Lang PO. Health benefits of aerobic training programs in adults aged 70 and over: a systematic review. Arch Gerontol Geriatr. 2017;69(1):110-127.

35. Lee PG, Jackson EA, Richardson CR. Exercise Prescriptions in Older Adults. Am Fam Physician 2017; 95(7):425-432.

36. Noradechanunt C, Worsley A, Groeller H. Thai Yoga improves physical function and well-being in older adults: A randomised controlled trial. J Sci Med Sport 2017;20(5):494-501.

37. Granacher U, Gollhofer A, Hortobágyi T, Kressig RW, Muehlbauer T. The importance of trunk musclestrength for balance, functionalperformance,

and fall preventionin seniors: a systematic review. Sports Med 2013;43(7):627-41.

38. Boylu AA.[The Relationship Between Housing And Quality Of Life In Older Ages]. Toplum ve Sosyal Hizmet 2013;24(1):145156.

39. Almeida ST, Soldera CL, Carli GA, Gomes I, Resende T de L. Analysis of extrinsic and intrinsic factors that predispose elderly individuals to fall. Rev Assoc Med Bras 2012; 58(4):427-433. 